\title{
Isolation and structure elucidation of anti-malarial principles from Terminalia mantaly H. Perrier stem bark
}

\author{
Babatunde SAMUEL* and Yemi Adekola ADEKUNLE
}

Pharmaceutical Chemistry Department, Faculty of Pharmacy, University of Ibadan, Nigeria. *Corresponding author; E-mail: tundebsamuel@gmail.com; Tel: +2348131951725

\author{
Received: 30- 05- 2020
}

Accepted: 01- 08- 2020

Published: 28- 02- 2021

\begin{abstract}
Emergence of malaria parasite resistance to drugs has raised global public health concerns for a compelling need to develop improved malaria therapy. This study is a bio-guided isolation of triterpenoid antimalarial compounds from Terminalia mantaly. Methanol extract of the plant was subjected to column chromatography, and eluted with a ternary solvent system gradient-wise. Two compounds, 1 and 2, were isolated and characterised by spectroscopic data (IR, ${ }^{1} \mathrm{H}$ and ${ }^{13} \mathrm{C}$ NMR, COSY, HMQC, HMBC) and by comparison with literature. Isolated compounds were investigated for antimalarial property by spectrophotometric determination of inhibition of $\beta$-Hematin formation, absorbance taken at $405 \mathrm{~nm}$. Results were analysed using Graghpad Prism ${ }^{\circledR}$ (6.0) and presented as mean $\mathrm{IC}_{50} \pm \mathrm{SEM}$. Statistical significance, determined using Student's t-test and one-way ANOVA, set at $\mathrm{p}$-value of 0.05 . Quantitative $\beta$-Hematin formation inhibitory activities gave $\mathrm{IC}_{50} \pm \mathrm{SEM}$ values of (compound $1 ; 4.434 \pm 0.47$ ), (compound $2 ; 5.140 \pm 4.2$ ) with (chloroquine; $0.335 \pm 0.1 \mathrm{mg} / \mathrm{ml}$ ). Compound 1 was identified as 2,3,19,23-tetrahydroxyolean-12-en-28-oic acid glucopyranoside (arjunglucoside I), and compound 2 as its aglycone, 2,3,19,23-tetrahydroxyolean-12-en-28-oic acid (arjungenin). This study provided credence for folkloric use of Terminalia mantaly to treat malaria, and this observed activity was probably due to these isolated triterpenoids.
\end{abstract}

(C) 2021 International Formulae Group. All rights reserved.

Keywords: $\beta$-Hematin, triterpenoids, nuclear magnetic resonance spectroscopy.

\section{INTRODUCTION}

Malaria is one of the most grievous parasitic infectious diseases caused by protozoa of the genus Plasmodium. It is one of the leading causes of death in many tropical regions including West African countries. About $74 \%$ of an estimated US $\$ 2.7$ billion spent on malaria control and elimination globally by governments of malaria endemic countries and other international parties was said to be spent in WHO African Region
(WHO, 2017). There is a close relationship between malaria and poverty. Majority of people affected by malaria live in world poorest regions. Malaria has been shown to be implicated in crippling poverty, less productivity, more work days missed and incurrence of expenses due to treatment. In 2016, an estimated 216 million malaria cases were reported worldwide, with estimated death of 445,000 . About $90 \%$ of the world malaria report in 2016 was said to be from WHO 
African Region, 7\% from WHO South-East Asia Region, and 2\% from WHO Eastern Mediterranean Region (WHO, 2017).

Nigeria is one of the most affected countries where morbidity and mortality rates due to malaria are high. The most vulnerable groups are children under five years (with an estimation of $75 \%$ malaria deaths in Nigeria between 1971-2015), and pregnant women. A recent assessment of malarial hazard and mortality in Nigeria showed that, despite decrease in malaria cases worldwide, malaria cases have increased exponentially in Nigeria resulting in deaths of many people especially children under age five (Kayode and Godwin, 2017).

Terminalia mantaly H. Perrier belongs to the family Combretaceae. It is widely grown as an excellent spreading shade and street tree. It is an ornamental plant locally known as Madagascar almond, French mantaly or umbrella tree. Terminalia mantaly has been used to treat fever, diarrhea, dysentery and bacterial infections (Ngouana et al., 2015). Biological screening efforts have revealed Terminalia mantaly to have antimalarial potential (Mbouna et al., 2018). Aqueous and ethanolic extracts from Terminalia mantaly stem bark have shown activity against clinical isolates of Candida albicans and Aspergillus fumigatus (Yapi et al., 2011). A study also showed fungicidal, synergistic inhibitory effects of Terminalia catappa, Terminalia mantaly and Monodora tenuifolia against clinical isolates of Candida albicans (Ngouana et al., 2015).

Medicinal plants have been a source of malaria therapy since the ancient times. It has been discovered that several plants have antimalarial properties (Ngbolua et al., 2011; Oluyemi and Samuel, 2017; Willcox et al., 2004). Extracts from bark of Cinchona officinalis and leaves of Artemisia апnиа are prototypical for the development of antimalarial drugs from natural products; while some plants have also demonstrated high level of antimalarial activities (Dawet et al., 2012; Adzu et al., 2008). However, resistance to currently available antimalarial agents has been reported (Wongsrichanalai and Meshnick, 2008).

Better understanding of the lifecycle of malaria parasite has offered a lot of advantages in rational approach to antimalarial drug discovery. During intraerythrocytic stage of Plasmodium life cycle, malarial parasite takes in hemoglobin from erythrocytes into the cytostome. Many small tubular vesicles containing hemoglobin from the cytostome fuse to food vacuole which is acidic (David et al., 2008). In the acidic $\mathrm{pH}$ of the food vacuole, hemoglobin is oxidized to methemoglobin and subsequently hydrolyzed by aspartic proteases into free heme $\left(\mathrm{Fe}^{+3}\right)$ and denatured globin. Further digestion takes place on globin via the actions of cysteine proteases, zinc containing metallopeptidase and exopeptidase in cytosol to produce amino acids for parasite protein synthesis and energy which are important for the development and the proliferation of the parasite (Rosa et al., 2005).

Accumulation of redox-active free heme (ferriprotoporphyrin IX [PPIXFe]) within the parasite food vacuole may reach as high level as $300-500 \mathrm{mM}$ (Wright et al., 2001a). Free heme $\left(\mathrm{Fe}^{3+}\right)$ produce reactive oxygen species and may cause oxidative stress in the parasites. This toxic nature of free heme leads to parasite death (Thomas et al, 2014). Malaria parasite protects itself from hemeinduced oxidative stress by effective heme detoxification mechanisms, primarily by converting free heme to hemozoin ( $\beta$-hematin) in the food vacuole (Ziegler et al., 2001). Betahematin formation assay is an in vitro method which has been validated by existing antimalarial agents, such as chloroquine and quinine, and it has been used to investigate antiplasmodial activity of medicinal plants (Vargas et al., 2011).

This research work aimed at isolating the bioactive substances responsible for the anti-plasmodial property of Terminalia mantaly stem bark, and to elucidate their chemical structures using their nuclear magnetic resonance (NMR) spectroscopic data. 


\section{MATERIALS AND METHODS}

\section{Plant sample preparation}

The stem bark of Terminalia mantaly $\mathrm{H}$.

Perrier was collected at the University of Ibadan botanical garden. The plant was authenticated and a voucher specimen deposited at the University of Ibadan Herbarium (UIH), Botany Department, with the number: UIH-22715.

\section{Extraction}

The plant sample was air-dried for 3 weeks and milled into powder. The sample was properly stored until used. About $1 \mathrm{~kg}$ was extracted with 7 litres of methanol using cold maceration method. The macerate was filtered and concentrated with rotary evaporator (Heidolph HB digital, Germany) at $<40{ }^{\circ} \mathrm{C}$. The concentrated extract was reduced to semisolid using water bath at $40 \pm 10{ }^{\circ} \mathrm{C}$ to allow it dry completely. The percentage yield of the dried extract was computed.

\section{Qualitative phytochemical screening}

Phytochemical screening was performed on the crude extract for the presence of alkaloids, saponins, tannins, triterpenes, cardiac glycosides, anthraquinones, steroids and flavonoids using standard procedures (Ayoola et al., 2008).

\section{Column chromatographic separation of crude extract}

About 20 grams of the crude extract was loaded on a $85 \mathrm{~cm} \times 6 \mathrm{~cm}$ column packed with 60-120 mesh size silica gel. It was then eluted with hexane, chloroform and methanol gradient-wise. The sample was initially eluted with hexane/chloroform (50:50), and polarity was gradually increased with the addition of chloroform and methanol as follows: Hexane/chloroform $\quad 20: 80, \quad 0: 100$; Chloroform/methanol 95:5, 90:10, 80:20, 70:30, 60:40, 50:50, 40:60, 30:70, 20:80\%. Two hundred and thirty, $30 \mathrm{ml}$, fractions were collected. Eight fractions labelled F1 to F8 were obtained based on their TLC profiling. Active fraction F7 was further purified with ethyl acetate to give a white crystalline compound $1(145 \mathrm{mg})$ and fraction F4 gave a white amorphous compound $2(35 \mathrm{mg})$ by preparatory TLC.

\section{Spectroscopic analysis of isolated compounds}

1D and 2D NMR data were obtained by dissolving the samples in DMSO- $\mathrm{d}_{\delta}$. Melting point was determined on Barnstead Electrothermal IA9000 and Infrared spectra obtained on Perkin Elmer Spectrum BX FTIR. In vitro Beta-Hematin formation assay Chemicals

Pyridine solution (Sigma), hydroxyethylpiperazine-N-[2-ethanesulphonic acid] (HEPES) solution $20 \mathrm{mM}, 0.1 \mathrm{M} \mathrm{NaOH}$, $1 \mathrm{M} \mathrm{HCl}$, chloroquine phosphate, bovine heme [Fe(III)PPX], glacial acetic acid, sodium acetate (BDH Chemicals, England), methanol, saturated acetate solution ( $\mathrm{pH} 5.0$ ).

\section{Sample preparation}

A concentration of $10 \mathrm{mg} / \mathrm{ml}$ of the eight column fractions (F1-F8) and the plant crude extract were made in methanol.

\section{Beta-Hematin formation assay}

The antimalarial potential of the plant sample was evaluated by the method described by Vargas et al. (2011). An aliquot, $10 \mu \mathrm{L}$, of each of the concentrations was placed inside four $2 \mathrm{ml}$ sized Eppendorf's tubes in triplicates. $1 \mathrm{M} \mathrm{HCl}, 10 \mu \mathrm{L}$, was added to all tubes. Then $100 \mu \mathrm{L}$ of freshly prepared bovine heme was added into the first two tubes. The plate was centrifuged at 900 rotations per minute for 5 minutes. Then $60 \mu \mathrm{L}$ of pre-warmed sodium acetate solution (pH5.0) was added to all tubes. The tubes were incubated at $60{ }^{\circ} \mathrm{C}$ for 90 minutes. Then $750 \mu \mathrm{L}$ of $15 \%$ pyridine in HEPES solution was added into first and third tubes and $750 \mu \mathrm{L}$ of HEPES solution ( $\mathrm{pH} 7.5$ ) was added into second and fourth tubes. The tubes were centrifuged at $900 \mathrm{rpm}$ for 5 minutes and allowed to settle for 15 minutes. An aliquot $(100 \mu \mathrm{L})$ of the supernatant was transferred into a non-sterilized $300 \mu \mathrm{L}$ 96-well plate and its absorbance taken at $405 \mathrm{~nm}$ with Rayto scientific RT-6100 microplate reader. 


\section{Qualitative determination of the inhibition of $\boldsymbol{\beta}$-hematin formation}

Each concentration analysed ( $\left.\mathrm{A}_{\text {Analysis }}\right)$ [first tube] has a blank (A Analysis;Blank) [second tube] which differed from the concentration by the addition of $750 \mu \mathrm{L}$ HEPES $20 \mathrm{mM}$ solution instead of $750 \mu \mathrm{L}$ pyridine solution. They were all prepared in triplicates.

The absorbance, at $405 \mathrm{~nm}$, of the complex due to the remaining hematin in wells was calculated by the formula:

$$
\Delta \mathrm{A}_{\text {Analysis }}=\mathrm{A}_{\text {Analysis }}-\mathrm{A}_{\text {Analysis:Blank }}
$$

For each tested concentration, a blank control $\left(\mathrm{A}_{\mathrm{CLT} ; \mathrm{Blank}}\right)$ [third tube] as well as its control (A CLTBlank:Blank ) [fourth tube] were prepared in triplicates under the same experimental conditions as described above. The blank control (AcLTBlank;Blank) had $750 \mu \mathrm{L}$ HEPES $20 \mathrm{mM}$ solution instead of $15 \%$ pyridine solution added to (A $\mathrm{A}_{\mathrm{CLT} \text {; Blank }}$ ).

The residual absorbance, at $405 \mathrm{~nm}$, of the sample independent from the inhibition of the beta-hematin complex was determined by the formula:

$\Delta \mathrm{A}_{\mathrm{CLT} ; \text { Blank }}=\mathrm{A}_{\mathrm{CLT} ; \text { Blank }}-\mathrm{A}_{\mathrm{CLTBlank} ; \text { Blank }}$
The resultant beta-hematin formation inhibitory effect induced by the sample being analyzed was computed by:

$\mathrm{I}_{\text {Analysis }}=\Delta \mathrm{A}_{\text {Analysis }}-\Delta \mathrm{A}_{\mathrm{CLT} ; \text { Blank }}$

Positive value for $\mathrm{I}_{\text {Analysis }}$ is considered a positive result or active concentration and negative value for $I_{\text {Analysis }}$ is considered negative result or inactive concentration.

\section{Quantitative determination of $\mathbf{5 0 \%}$ inhibitory concentration $\left(\mathrm{IC}_{50} \mathrm{mg} / \mathrm{ml}\right)$}

The above procedure was repeated for the most active fractions in six concentrations $(10 \mathrm{mg} / \mathrm{mL}, 5 \mathrm{mg} / \mathrm{mL}, 2.5 \mathrm{mg} / \mathrm{mL}, 1.25$ $\mathrm{mg} / \mathrm{mL}, 0.625 \mathrm{mg} / \mathrm{mL}$ and $0.3125 \mathrm{mg} / \mathrm{mL}$ ). The experiment was carried out in triplicates. Chloroquine was used as reference drug.

\section{Statistical analysis}

Experimental data ( $\left.\mathrm{I}_{\text {Analysis }}\right)$ expressed as mean \pm standard error of the mean. Statistical significance was determined using unpaired $t-$ test and one-way ANOVA followed by post hoc test. A P-value of $<0.05$ was considered significant. Activities were reported as $\mathrm{IC}_{50} \pm \mathrm{SEM} \mathrm{mg} / \mathrm{ml}$. GraphPad Prism ${ }^{\circledR}$ (6.0) was used.

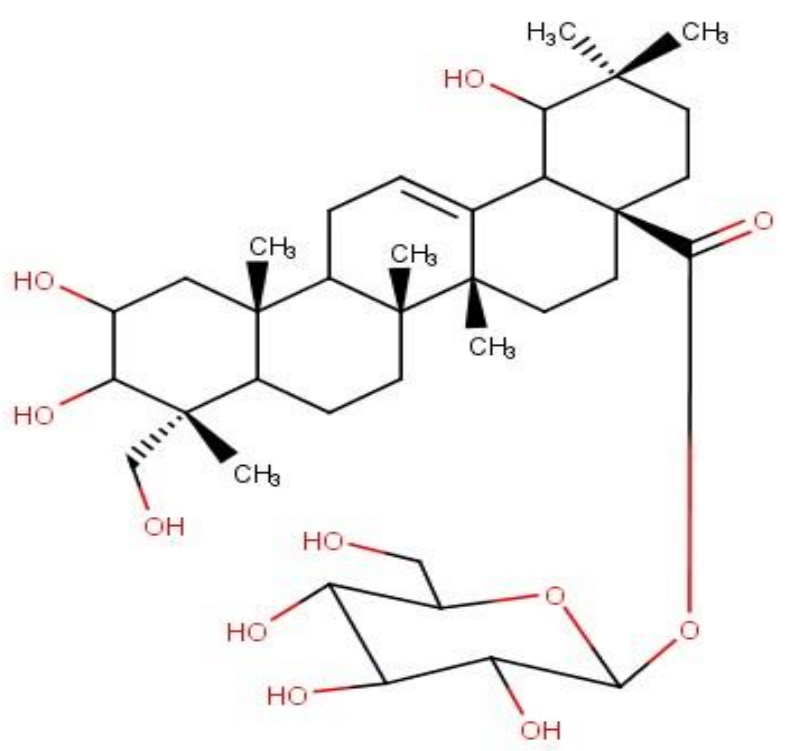

Compound 1: $2 \alpha, 3 \beta, 19 \alpha, 23$-tetrahydroxyolean-12-en-28-oic acid glucopyranoside (Arjunglucoside I). 


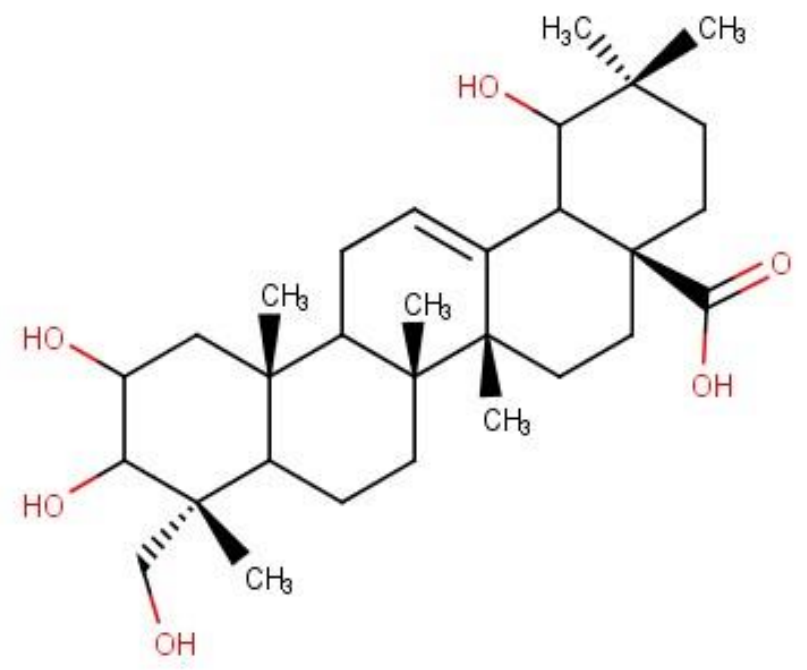

Compound 2: $2 \alpha, 3 \beta, 19 \alpha, 23$-tetrahydroxyolean-12-en-28-oic acid (Arjungenin).

\section{RESULTS}

Extraction of Terminalia mantaly stem bark with methanol gave 137 grams of crude extract with percent yield of $13.7 \%$.

Phytochemical screening of the crude extract indicated the presence of saponins, tannins, anthraquinones, terpenoinds, steroids, flavonoids and alkaloids in varied degrees.

Column chromatographic separation gave compound 1 (145 mg; $\mathrm{R} f$ of 0.2 in CM 90\%:10\%) and compound 2 (35 mg; R $f$ of 0.5 in CM 90\%:10\%). Compound $\mathbf{1}$ was a white crystalline powder, melting point rage of 219$223^{\circ} \mathrm{C}$.

\section{Spectroscopic data}

Compound 1 (0.725\%): White crystalline powder, melting point $219-223{ }^{\circ} \mathrm{C}$. IR (KBr pellet): $1179.80 \mathrm{~cm}^{-1}, 1260.00 \mathrm{~cm}^{-1}$, $1070.02 \mathrm{~cm}^{-1}, 1628.83 \mathrm{~cm}^{-1}, 1727.91 \mathrm{~cm}^{-1}$, $2935.16 \mathrm{~cm}^{-1}, 3435.52 \mathrm{~cm}^{-1}$. ${ }^{1} \mathrm{H}$ NMR (DMSO$\left.\mathrm{d}_{\delta}\right): \delta_{\mathrm{H}} 0.6031,0.8423,0.8660,0.8889,1.0790$ and 1.2115 (each methyl group, s); $5.2377(1 \mathrm{H}$, dd, H-12). ${ }^{13} \mathrm{C}$ NMR (DMSO-d $\delta$ ): $\delta_{\mathrm{C}} 16.9331$, 23.7920, 25.0781 and 28.5076; 143.6881 (C13), 122.8184 (C-12), 80.5929 (C-3), 84.6654 (C-19), $43.3854 \quad$ (C-18), $67.5180 \quad$ (C-2),
64.2979 (C-23), 182.28 (C-28), 28.5076 (C29); sugar moiety: $\delta_{\mathrm{C}} 94.7395,78.2351$, 76.9490, 72.8765, 69.8757, and 61.0577.

Compound 2 (0.175\%): White amorphous powder. IR: $3419.00 \mathrm{~cm}^{-1}, 1018.29$ $\mathrm{cm}^{-1}, 1643.76 \mathrm{~cm}^{-1}, 2979.00 \mathrm{~cm}^{-1} .{ }^{1} \mathrm{H}$ NMR $\left(\mathrm{DMSO}_{\delta}\right): \quad \delta_{\mathrm{H}} \quad 0.6605, \quad 0.8163,0.8741$, 1.0772, 1.1988 and 1.2307 (each methyl group, s); $5.1319\left(1 \mathrm{H}\right.$, brs, H-12). ${ }^{13} \mathrm{C}$ NMR (DMSO$\left.\mathrm{d}_{\delta}\right) ; 124.59$ (C-12), 144.69 (C-13), 81.4173 (C3), 67.4601 (C-2), 48.1346 (C-9), 84.6382 (C19), 182. 28 (C-28), 25.5883 (C-30), 64.3926 (C-23).

\section{Antimalarial results}

The results of the qualitative determination of $\beta$-hematin formation inhibitory property of the column fractions $(\mathrm{F} 1$ - F8) were shown in Table 1. Fraction F8 had the highest activity, followed by F4 and then F7 with $\mathrm{I}_{\text {Analysis }}(\mathrm{Mean} \pm \mathrm{SEM})$ of $0.201 \pm 0.0299$, $0.181 \pm 0.0708$ and $0.145 \pm 0.0122$ respectively. F7 yielded compound 1 and F4 yielded compound 2. Compound 1 and compound 2 showed appreciably high activity at inhibiting beta-hematin formation. The mean $\mathrm{IC}_{50} \mathrm{mg} / \mathrm{ml}$ \pm standard error of the mean values and P- 
values are given in Table 2 . In determining the quantitative beta-hematin formation inhibitory activity at different concentrations, compound 1 with $\mathrm{IC}_{50} \pm \mathrm{SEM}$ of $4.434 \pm 0.47 \mathrm{mg} / \mathrm{ml}$ was more active than its aglycone (compound 2) with $\mathrm{IC}_{50} \pm \mathrm{SEM}$ of $5.140 \pm 4.2 \mathrm{mg} / \mathrm{ml}$. Chloroquine was used as the standard
$\left(\mathrm{IC}_{50} \pm \mathrm{SEM}=0.335 \pm 0.1 \mathrm{mg} / \mathrm{ml}\right)$. When compared the activity of the active fractions with the activity of chloroquine using one-way ANOVA post analysis Tukey's multiple comparison test, chloroquine was statistically more active at the same tested concentrations.

Table 1: Qualitative determination of $\beta$-hematin formation inhibition of column fractions and chloroquine.

\begin{tabular}{cc}
\hline Fractions $\mathbf{( 1 0} \mathbf{~ m g / m l )}$ & I \\
\hline F1 & $0.115 \pm 0.0112$ \\
F2 & $0.103 \pm 0.0344$ \\
F3 & $0.079 \pm 0.0255$ \\
F4 & $0.181 \pm 0.0708$ \\
F5 & $0.102 \pm 0.0438$ \\
F6 & $0.135 \pm 0.0170$ \\
F7 & $0.145 \pm 0.0122$ \\
F8 & $0.201 \pm 0.0299$ \\
WE & $0.167 \pm 0.0325$ \\
Chloroquine $4 \mathrm{mg} / \mathrm{ml}$ & $0.337 \pm 0.0779$ \\
\hline
\end{tabular}

Table 2: $\mathrm{IC}_{50} \mathrm{mg} / \mathrm{ml}$ determination of $\beta$-hematin formation inhibition of isolated compounds and chloroquine.

\begin{tabular}{lll}
\hline & IC $_{\mathbf{5 0}} \mathbf{~ m g} / \mathbf{m L}$ mean \pm SEM & T-test P value \\
\hline Arjunglucoside I & $4.434 \pm 0.47$ & $\mathrm{P}<0.05$ \\
Arjungenin & $5.140 \pm 4.2$ & $\mathrm{P}<0.05$ \\
Chloroquine & $0.335 \pm 0.1$ & $\mathrm{P}<0.05$ \\
\hline
\end{tabular}




\section{DISCUSSION}

Malaria is a life-threatening disease caused by Plasmodium parasites. The parasite digestion of hemoglobin in the food vacuole produces high quantity of free heme $\left(\mathrm{Fe}^{+3}\right)$; this redox active species is toxic to the parasite and can cause cell lysis (Sanjay et al, 2007). Consequently, the parasite converts the toxic free heme to non-toxic hemozoin (Egan, 2001). Hemozoin ( $\beta$-hematin) formation is a validated pathway by with malaria parasite detoxifies free heme. Thus, it has been validated that classical antimalarial drugs such as chloroquine and quinine exhibit their antiplasmodial effect by enhancing heme toxicity through inhibition of hemozoin formation (Kumar et al., 2007). This in vitro synthesis of hemozoin in the presence of acetate solution at carefully optimized experimental conditions of temperature and $\mathrm{pH}$ (Egan et al., 2001) has been validated, absorbance taken at $405 \mathrm{~nm}$, for routine screening of plant extracts for anti-malarial activity (Vargas et al., 2011).

In this study, two triterpenoids of oleanane type were isolated from fractions 4 and 7 through chromatographic separation. They were identified as arjungenin and its glycoside, arjunglucoside I. Compound 1 IR ( $\mathrm{KBr}$ pellet) spectrum gave signals at 1179.80 $\mathrm{cm}^{-1}$ and $1260.00 \mathrm{~cm}^{-1}$ which are indication of the presence of $\mathrm{C}-\mathrm{O}$. The signal observed at $1070.02 \mathrm{~cm}^{-1}$ was assigned to the presence of a glycosidic linkage in the molecule. Signal at $1628.83 \mathrm{~cm}^{-1}$ showed the presence of $\mathrm{C}=\mathrm{C}$ group. The sharp absorption signal at 1727.91 $\mathrm{cm}^{-1}$ is indicative of ester carbonyl group $(\mathrm{C}=\mathrm{O})$. There was a signal at $2935.16 \mathrm{~cm}^{-1}$ which is an indication of the presence of saturated C-H group while that at $3435.52 \mathrm{~cm}^{-}$ ${ }^{1}$ showed presence of $\mathrm{O}-\mathrm{H}$ bond. ${ }^{1} \mathrm{H}$ and ${ }^{13} \mathrm{C}$ NMR spectra data signals were characteristic of an oleanane-type triterpenoid with one sugar moiety. The ${ }^{1} \mathrm{H}$ NMR (DMSO, $\mathrm{d}_{\delta}$ ) gave signals for six methyl groups attached to quaternary carbons at $\delta_{\mathrm{H}} 0.6031,0.8423,0.8660,0.8889$, 1.0790 and 1.2115. HMQC revealed a crosspeak correlation of an unsaturated carbon with an olefinic hydrogen which resonates at $\delta_{\mathrm{H}}$ $5.2377(\mathrm{~d}, 1 \mathrm{H})$, assigned to $\mathrm{C}-12$. An oxygenated hydrogen can be observed $\delta_{\mathrm{H}}$ 3.1292 assigned to C-3. ${ }^{13} \mathrm{C}$ NMR (DMSO, $\mathrm{d}_{\delta}$ ) indicated the presence of a methine carbon at $\delta_{\mathrm{C}} 122.8184$ and a quaternary carbon at $\delta_{\mathrm{C}}$ 143.6891 assigned to $\mathrm{C}-12$ and $\mathrm{C}-13$ respectively (Abdullahi et al, 2012). This confirmed the olefinic proton observed at $\delta_{\mathrm{H}}$ 5.2377 which ${ }^{13} \mathrm{CNMR}$ showed to be a methine. The chemical shifts of $\mathrm{C}-12$ and $\mathrm{C}-13$ suggests that compound $\mathbf{1}$ is a $\Delta^{12}$-unsaturated triterpenoid. C-3 gave a signal resonating at $\delta_{\mathrm{C}} 80.5929$; and one anomeric carbon signal resonating at $\delta_{\mathrm{C}} 94.7395$, which is characteristic of the carbon forming the glycosidic linkage (Bharathi et al, 2013). The peaks at $\delta_{\mathrm{C}} 94.7395,78.2351,76.9490$, $72.8765,69.8757$, and 61.0577 are indicative of the presence of hexose sugar unit carbon atoms with glycosidic ester linkage at C-28. NMR data suggested nine oxygen bearing carbons with four $-\mathrm{OH}-$ groups which are part of the triterpenoid skeleton $-67.5180(\mathrm{C}-2)$, 80.5929 (C-3), 84.6654 (C19), 64.2979 (C-23). A carbonyl carbon was observed at $\delta_{\mathrm{C}} 182.28$. Extensive ${ }^{1} \mathrm{H}$ and ${ }^{13} \mathrm{C}$ NMR data comparison with those previously published showed that spectroscopic data of compound $\mathbf{1}$ were consistent with those reported for 2,3,19,23tetrahydroxyolean-12-en-28-oic acid glucopyranoside (Arjunglucoside I) (Bharathi et al, 2013; Marthe et al., 2017).

Compound $\mathbf{2}$ is a white amorphous solid. IR data showed a very strong and broad absorption at $3419.00 \mathrm{~cm}^{-1}$ which is indicative of the presence of $\mathrm{O}-\mathrm{H}$ group. The prominent absorption at $1018.29 \mathrm{~cm}^{-1}$ for $\mathrm{C}-\mathrm{O}$ bond confirms alcoholic $\mathrm{OH}$. Signal at $1643.76 \mathrm{~cm}^{-1}$ is indicative of $\mathrm{C}=\mathrm{O}$ group. The spectrum also showed the presence of saturated $\mathrm{C}-\mathrm{H}$ group at $2979.00 \mathrm{~cm}^{-1}$. The NMR data for compound 2 are similar to those recorded for compound $\mathbf{1}$ with only signals for sugar moiety missing. The ${ }^{1} \mathrm{H}$ NMR and ${ }^{13} \mathrm{C}$ NMR (DMSO, $\mathrm{d}_{\delta}$ ) data gave signals that were characteristic of $\Delta^{12}$ unsaturated oleanane triterpenoid (Singh et al, 2004). The ${ }^{1} \mathrm{H}$ NMR has six methyl singlets at $\delta_{\mathrm{H}} 0.6605,0.8163,0.8741,1.0772,1.1988$ and 1.2307. A characteristic down-field proton at $\delta_{\mathrm{H}} 5.1319(\mathrm{~s}, \mathrm{br}, 1 \mathrm{H})$ gave a correlation with an olefinic carbon at $\delta_{\mathrm{C}} 124.59$ in the HMQC 
spectrum; this was assigned to C-12. Saturated carbon C-13 was observed at $\delta_{\mathrm{C}} 144.69$ and a carbonyl carbon at $\delta_{\mathrm{C}} 182.28$. The signal observed at $\delta_{\mathrm{H}} 3.0708(1 \mathrm{H}, \mathrm{s})$ is suggestive of an oxygenated proton typically at C-3; HMQC showed its correlation with $\delta_{\mathrm{C}} 81.4173$. Similar to compound $\mathbf{1}$, four oxygen-bearing carbons with $-\mathrm{OH}-$ groups at $\delta_{\mathrm{C}} 67.4601(\mathrm{C}-2)$, 81.4173 (C-3), 84.6382 (C19), 64.3926 (C-23) were observed. All these data suggested compound $\mathbf{2}$ to be aglycone of compound $\mathbf{1}$. Comparison of compound $\mathbf{2}$ data with literature suggested the compound to be $2,3,19,23$ tetrahydroxyolean-12-en-28-oic acid, arjungenin (Bharathi et al., 2013; Marthe et al., 2017).

Triterpenes are a class of naturally diverse compounds derived from squalene. They are one of the most abundant secondary metabolites found in Combretaceae plants. They may be tetracyclic or pentacyclic. Based on their chemistry, triterpenoids can be ursane, oleanane or lupane. They can occur as free triterpenoids, as triterpenic esters or as triterpenic glycosides. Triterpenoids have extensively reviewed biological activities which include anticancer, antibacterial, antiinflammatory (Petr et al., 2006), hepatoprotective, anti-Human Immunodeficiency Virus (anti-HIV), antioxidant, analgesic, anxiolytic, immunomodulatory, antimycotic (Jainendra et al., 2018) antimalarial activities (Ronan et al., 2009). Literature revealed that, from the 1990s, tannins and triterpenes are the main compounds from Combretaceae family that have shown promising antiplasmodial activity (Fournet and Munoz, 2002).

The antiplasmodial activity of the isolated compounds was expressed as $\mathrm{IC}_{50}$ $\mathrm{mg} / \mathrm{ml} \pm \mathrm{SEM}$. Tested at similar concentrations with the reference drug chloroquine, compound 1 (arjunglucoside I) has $\mathrm{IC}_{50} \mathrm{mg} / \mathrm{ml}$ of 4.434 \pm 0.47 ; and compound 2 (arjungenin) has $\mathrm{IC}_{50} \mathrm{mg} / \mathrm{ml}$ of $5.140 \pm 4.2$. Arjungenin and arjunglucoside I have been isolated from Terminalia bellerica (Min et al., 2014), Terminalia chebula (Bharathi et al., 2013), Combretum racemosum (Gossan et al., 2016). The compounds were recently identified and screened against three pathogenic yeasts (Candida albicans, Candida parapsilosis and Candida krusei) and four enzymes of metabolic significance (glucose-6-phosphate dehydrogenase, human erythrocyte carbonic anhydrase I and II, and glutathione Stransferase) with activity comparable to the drug standard used (Marthe et al., 2017). Arjungenin, isolated from Terminalia chebula, was reported to have potent inhibitory effect on Epstein-Barr Virus Early Antigen (EBV-EA) induced by 12-O-tetradecanoylphorbol-13acetate (TPA) in Raji cells; its activity higher than that of arjunglucoside I. Arjungenin also showed inhibitory effect in an in vivo carcinogenesis test conducted to promote skin tumour on mouse skin. It also showed moderate cytotoxic effect against HL60 cells (Manosroi et al., 2013).

The results of this study showed that there is scientific basis for the ethnobotanical usage of the Terminalia mantaly to treat malaria.

\section{Conclusion}

This study reported isolation and structural characterization of two oleananetype triterpenoids identified as arjungenin and its glycoside, arjunglucoside $\mathrm{I}$ with antimalarial properties against in vitro $\beta$ Hematin synthesis. Therefore, this study provided support for the traditional use of Terminalia mantaly stem bark for the treatment of malarial fever. Further isolation of other antimalarial compounds from Terminalia mantaly stem bark; and insilico studies towards the development of a lead compound for the treatment of malaria are ongoing. Chronic and acute toxicity profiles of the extracts and isolated compounds must be clearly established before they can be considered for application in humans.

\section{COMPETING INTERESTS}

The authors declare that there is no competing interest.

\section{AUTHORS' CONTRIBUTIONS}

BS designed and supervised the study. YAA carried out the chemical and biological 
aspects of the research and drafted the manuscript. The manuscript was revised and its final version agreed on by both authors.

\section{ACKNOWLEDGMENTS}

YAA was a recipient of Graduate Assistantship and scholarship from the University of Ibadan, Ibadan. Authors' acknowledgement goes to Professor Adeboye Adejare of the Philadelphia College of Pharmacy, University of the Sciences, Philadelphia, USA, for the assistance in NMR analysis.

\section{REFERENCES}

Abdullahi M, Kolo I, Adebayo O, Joseph O Amupitan3, Majekodumi F, Okogun JI. 2012. Isolation and Elucidation of Three Triterpenoids and Its Antimycobacterial Activty of Terminalia Avicennioides. American Journal of Organic Chemistry, 2(2): $\quad 14-20 \quad$ DOI: 10.5923/j.ajoc. 20120202.03

Adzu B, Zakariya ST, Auta IK, Katsayal UA. 2008. Assessing the potency of Pedilanthus tithymaloides latex against Plasmodium berghei infected mice. Int. J. Biol. Chem. Sci., 2(2): 216-219. DOI: 10.4314/ijbcs.v2i2.39742

Ayoola GA, Coker HAB, Adesegun SA, Adepoju-Bello AA, Obaweya K, Ezennia EC, Atangbayila TO. 2008. Phytochemical screening and antioxidant activities of some selected medicinal plants used for malaria therapy in Southwest Nigeria. Tropical Journal of Pharmaceutical Research, 7(3): 10191024. DOI: $10.4314 /$ tjpr.v7i3.14686

Bharathi A, Yan-Hong W, Mei W, Yun-Heng S, Ikhlas AK. 2013. Simultaneous Determination and Characterization of Tannins and Triterpene Saponins from the Fruits of Various Species of Terminalia and Phyllantus emblica Using a UHPLC-UV-MS Method: Application to Triphala. Planta Med., 79(02): 181188. DOI: $10.1055 / \mathrm{s}-0032-1328089$

David AE, Michael TM, Dean H, Shuo C, Gina Z, Keith AJ. 2008. Four distinct pathways of hemoglobin uptake in the malaria parasite Plasmodium falciparum. PNAS, 105(7): 2463-2468. DOI: https://doi.org/10.1073/pnas.0711067105

Dawet A, Gregory I, anyanwu GM, Dede PM, Uzoigwe NR, Onyekwelu NA. 2012. In vivo antimalarial activity of the ethanolic leaf extract of Hyptis suaveolens poit on Plasmodium berghei in Mice. Int. J. Biol. Chem. Sci., 6(1): 117-127. DOI: http://dx.doi.org/10.4314/ijbcs.v6i1.11

Egan TJ. 2001. Structure-function relationship in chloroquine and related 4aminoquinoline antimalarial. Mini Reviews in Medicinal Chemistry, 1(1): 113-123.

DOI: https://doi.org/10.2174/13895570134071 88

Egan TJ, Mavuso WW, Ncokazi KK. 2001. The mechanism of $\beta$-hematin formation in acetate solution. Parallels between hemozoin formation and biomineralization processes. Biochemistry 40: 204-213. DOI: https://doi.org/10.1021/bis0013501

Fournet A, Munoz V. 2002. Natural products as trypanocidal, antileishmanial and antimalarial drugs. Current Topical Medicinal Chemistry, 2: 1215-1238. DOI: $10.2174 / 1568026023393011$

Gossan ADPA, Magid AA, Yao-Kouassi PA, Josse J, Gangloff SC, Morjani H, Voutquenne-Nazabadioko L. 2016. Antibacterial and cytotoxic triterpenoids from the roots of Combretum racemosum. Fitoterapia, 110: 89-95. DOI: https://doi.org/10.1016/j.fitote.2016.03.0 02

Jainendra KB, Praveen KK, Vasudha B, Narender B. 2018. Triterpenoids: A review. International Journal of Research in Pharmacy and Pharmaceutical Sciences, 3(2): 91-96.

Kayode AA, Godwin EA. 2017. Historical assessment of malaria hazard and mortality in Nigeria - cases and deaths: 1955-2015. International Journal of Environment and Bioenergy, 12(1): 3046.

Kumar S, Mithu G, Vinay C, Pallab M, Uday B. 2007. Antimalarial drugs inhibiting 
hemozoin ( $\beta$-hematin) formation: A mechanistic update. Life Sciences, 80: 813-828.

DOI: https://doi.org/10.1016/j.lfs.2006.11.008

Manosroi A, Pensak J, Eri O, Ayako Y, Makoto F, Ken Y, Harukuni T, Nobutaka S, Jiradei M, Toshihiro A. 2013. Biological activities of phenolic compounds and triterpenoids from the galls of Terminalia chebula. Chemistry and Biodiversity, 10: 1448-1463. DOI: https://doi.org/10.1002/cbdv.201300149

Marthe ATT, Kammalac TN, Sebastian G, Rufin MTK, Abdulselam A, Muslum K, Veysel C, Ramazan D, Silvere AN, Etienne T, Norbert S, Bruno NL, Fabrice FB. 2017. Compounds from Terminalia mantaly L (Combretaceae) stem bark exhibit potent inhibition against some pathogenic yeasts and enzymes of metabolic significance. Medicines, 4(6): 1-12.

DOI: https://doi.org/10.3390/medicines401000 6

Mbouna DJC, Rufin MTK, Rodrigue K, Lauve RYT, Patrick VTF, Brice MTT, Dinkar S, Fabrice FB. 2018. Potent antiplasmodial extracts from Terminalia mantaly and Terminalia superba. Malaria Journal, 17: $142 . \quad$ DOI: https://doi.org/10.1186/s12936-0182298-1

Min HY, Zulfiqar A, Ikhlas A, Shabana IK. 2014. Anti-inflammatory Activity of Constituents Isolated from Terminalia chebula. Natural Product Communications, 9(7): 965-968. DOI: https://doi.org/10.1177/1934578X14009 00721

Ngbolua KN, Rakotoarimanana H, Rafatro H, Ratsimamanga US, Mudogo V, Mpiana PT. 2011. Comparative antimalarial and cytotoxic activities of two Vernonia species: $V$. amygdalina from the Democratic Republic of Congo and $V$. cinerea subsp vialis endemic to Madagascar. Int. J. Biol. Chem. Sci., 5(1): 345-353. DOI: 10.4314/ijbcs.v5i1.68111

Ngouana TK, Mbouna CDJ, Kuipou RMT, Tchuenmohne MAT, Zeuko'o EM,
Ngouana V, Mallie M, Bertout S, Boyom FF. 2015. Potent and synergistic extract combinations from Terminalia catappa, Terminalia mantaly and Monodora tenuifolia against pathogenic yeasts. Medicines 2: 220-235. DOI: https://doi.org/10.3390/medicines2030220

Oluyemi M, Samuel BB. 2017. In vitro screening of ten Combretaceae plants for antimalarial activities applying the inhibition of beta-hematin formation. Int. J. Biol. Chem. Sci., 11(6): 2971-2981. DOI: 10.4314/ijbcs.v11i6.33

Petr D, Marian H, David V, Alica H, Miroslav K, David B, Lenka M, Milan U, Jan S. 2006. Review: Pharmacological activities of natural triterpenoids and their therapeutic implications. Natural Products Reports, 23(3): 394-411. DOI: https://doi.org/10.3390/medicines2030220

Ronan B, Ademir de Jesus SJ, Alaíde Braga de Oliveira. 2009. Plant-derived antimalarial agents: New leads and efficient phytomedicines. Part II. Non-alkaloidal natural products. Molecules, 14: 30373072.

DOI: https://doi.org/10.3390/molecules 140830 37

Rosa MR, Babu LT, Rafael BF. 2005. Polyamine transport in parasites: A potential target for new antiparasitic drug development. Comparative Biochemistry and Physiology Part C: Toxicology \& Pharmacology, 140(2): 151-164. DOI: https://doi.org/10.1016/j.cca.2005.02.006

Sanjay K, Mithu G, Vinay C, Pallab M, Uday B. 2007. Antimalarial drugs inhibiting hemozoin ( $\beta$-hematin) formation: A mechanistic update. Life Sciences, 80(9): 813-828.

DOI: https://doi.org/10.1016/j.lfs.2006.11.008

Singh DV, Gupta MM, Tripathi AK, Prajapati V, Kumar S. 2004. Arjunetin from Terminalia arjuna as an insect feedingdeterrent and growth inhibitor. Phytother. Res., 18: 131-134. DOI: https://doi.org/10.1002/ptr.1383

Thomas A, Nicholas F, Richard A, Paul M, Stephen AW, Giancarlo AB. 2014. Rapid kill of malaria parasites by artemisinin 
and semi-synthetic endoperoxides involves ROS-dependent depolarization of the membrane potential. Journal of Antimicrobial Chemotherapy, 69(4): 1005-1016.

DOI: https://doi.org/10.1093/jac/dkt486

Vargas S, Ndjoko IK, Hay AE, Ioset JR, Wittlin S, Hostettmann K. 2011. Screening medicinal plants for the detection of novel antimalarial products applying the inhibition of $\beta$-hematin formation. Journal of Pharmaceutical and Biomedical Analysis, 56: 880-886. DOI:

https://doi.org/10.3390/molecules 140830 37

WHO (World Health Organization). 2017. World Malaria Report 2017. WHO, Geneva.

Willcox M, Burford G, Bodeker G, Rasoanaivo P. 2004. An overview of ethnobotanical studies on plants used for the treatment of malaria. In Traditional Medicinal Plants and Malaria. CRC Press: Boca Raton 187-197.

Wongsrichanalai C, Meshnick SR. 2008. Declining artesunate/mefloquine efficacy against falciparum malaria on the Cambodia-Thailand border. Emerging Infectious Diseases, 14: 716-719. DOI: 10.3201/eid1405.071601

Wright AD, Wang H, Gurrath M, Konig GM, Kocak G, Neumann G, Loria P, Foley M, Tilley L. 2001a. Inhibition of heme detoxification processes underlies the antimalarial activity of terpene isonitrile compounds from marine sponges. Journal of Medicinal Chemistry, 44(6): 873-885. DOI: 10.1021/jm0010724

Yapi GY, Adou KM, Ackah JAB, Djaman AJ. 2011. Evaluation of the antifungal activity and purification test of the active ingredients of extracts of Terminalia mantaly (H. Perrier), Combretaceae, on the in vitro growth of Candida albicans. Bull. Soc. R. sci. Liege, 80: 953-964.

Ziegler J, Linck R, Wright DW. 2001. Heme aggregation inhibitors: antimalarial drugs targeting an essential biomineralization process. Current Medicinal Chemistry, 8(2): 171-189. DOI: https://doi.org/10.2174/09298670 13373840 